\title{
Analysis of cell proliferation index using the Ki-67 Antigen in odontogenic keratocyst: a systematic review
}

\author{
Juliana Portes, ${ }^{1}$ Danielle Castex Conde, ${ }^{1,2}$ Eliane Pedra Dias ${ }^{1,3}$ \\ ${ }^{1}$ Postgraduate Program in Pathology, Medical School, Fluminense Federal University (UFF), Niterói, RJ, Brazil \\ 2Department of Dentistry, School of Dentistry, Veiga de Almeida University (UVA), Rio de Janeiro, RJ, Brazil \\ ${ }^{3}$ Department Laboratory Medicine and Pathology, Institut Gustave Roussy, Paris, France \\ - Conflicts of interest: none declared.
}

Abstract

Objective: this review aims to analyze scientific articles about cell proliferation index using Ki-67 in odontogenic keratocyst and compare these papers to estimate the average index of this lesion. Material and Methods: two researchers performed a literature search independently in the MEDLINE/PubMed database and 28 articles containing relevant data were selected. Results: the immunohistochemical analysis methodology showed great variability among all the papers, with unclear and unified methodologies, making the comparison among different studies difficult. Conclusion: considering odontogenic keratocyst as a lesion with an uncommon clinical behavior, an adequate classification for it is necessary, so an appropriate treatment with a good prognosis for the patient can be established according to its nature. A standardization is needed so immunohistochemical analyses will find reliable data to classify properly this lesion.

Keywords: Odontogenic keratocyst; Ki-67 antigen; Proliferation index.

\section{Introduction}

$\mathrm{T}$ The odontogenic keratocyst (OKC) was first classified as an odontogenic developmental cyst by Pindborg \& Kramer (1971), on the first official classification of odontogenic cysts and tumors by the World Health Organization (WHO). ${ }^{1}$ However, this lesion has three characteristics that raised discussions about its classification, which are locally destructive and aggressive behavior, high recurrence index and tendency toward multiplicity. ${ }^{2}$ In 2005, the WHO changed the classification of OKC to an odontogenic tumor, based on its high cell proliferation activity when compared to other odontogenic cysts and the presence of mutations in $\mathrm{p} 53$ and patched $(\mathrm{PTCH})$ genes that are also found in other neoplasms. ${ }^{2}$

Some authors did not accept this new classification, claiming that the existing evidence are insufficient to support the neoplastic origin of OKC and that further researches are needed. ${ }^{3}$ The $\mathrm{WHO}$ published its new classification in 2017, and OKC was again categorized as an odontogenic cyst. ${ }^{3}$

OKC represents about 10 to $20 \%$ of all odontogenic cysts, usually occurring between the second and third decade of life, with a slight predilection for men. ${ }^{3}$ The mandible bone is often affected ${ }^{4}$ and the cyst can be solitary or multiple - the last former is usually one of the components of inherited nevoid basal cell carcinoma syndrome (NBCCS). ${ }^{4,5}$
The evaluation of cell proliferation activity is one of the most common methods to assess the biological behavior of a lesion, being reported as an important prognostic marker and indicator of biological aggressiveness. ${ }^{5,6-8}$

The Ki-67 antigen is a highly specific marker of proliferating cells $s^{4,6-8}$ and has been widely used to evaluate the proliferative activity of preneoplastic and neoplastic lesions. ${ }^{5-7,9}$ This protein is present in all phases of the cell cycle, except in the G0 phase $e^{4,6-12}$, with a 60-90 minutes half-life. ${ }^{11}$

Over the years, many researches have evaluated the proliferative activity of OKC cells, comparing it to other cysts and tumors to better understand its pathogenesis and behavior. ${ }^{4,5,7,8,11-21}$ However, each study presents a different cell proliferation index (PI) and the methodology used is not always clear, making the comparison between the OKC index with other odontogenic lesions difficult, impairing the improvement of our knowledge about its nature and biological behavior, as well as the possibility of using Ki-67 as a prognostic marker for OKC.

This review aims to analyze and compare scientific articles that used Ki-67 as reference to evaluate the cell proliferation activity in OKC, comparing their methodology and results to define an average PI for OKC to facilitate future studies and comparisons. To the best of our knowledge, this is the first systematic review about this issue. 


\section{Material and Methods}

Two researchers, independently, conducted a literature search on the MEDLINE/PubMed database in June 2018. The search had no year restriction, using the abstract format and sorted by most recent. The Medical Subject Headings (MeSH) terms used were: Ki-67 antigen, odontogenic cyst, keratocysts and mitotic index. Those words were combined with other terms: odontogenic keratocyst, keratocystic odontogenic tumor, Ki-67 and cell proliferation index.

The search was performed in two stages: the first used the keywords chosen in different combinations, and the articles were selected based on their titles. Articles that were case reports and that were not in English language were excluded.

On the second stage, the researchers accessed the full texts of articles that were considered eligible for inclusion for further evaluation and selection. Some studies were excluded according to the established exclusion criteria: articles with an unclear methodology, articles without the PI, and articles that used NBCCS-associated OKC as samples. However, for articles that included syndromic and non-syndromic OKC in their samples with individualized results, only sporadic OKC was considered. . $^{10,19,22}$ The same approach was taken with the article that included recurrent and non-recurrent $\mathrm{OKC}$, only the last one was considered. ${ }^{9,22}$

From the various keywords combinations, 54 papers were pre-selected respecting the exclusion criteria for stage one. All articles appeared repeatedly in the different searches, these were only counted once, justifying the total of papers selected in this stage (Figure 1).

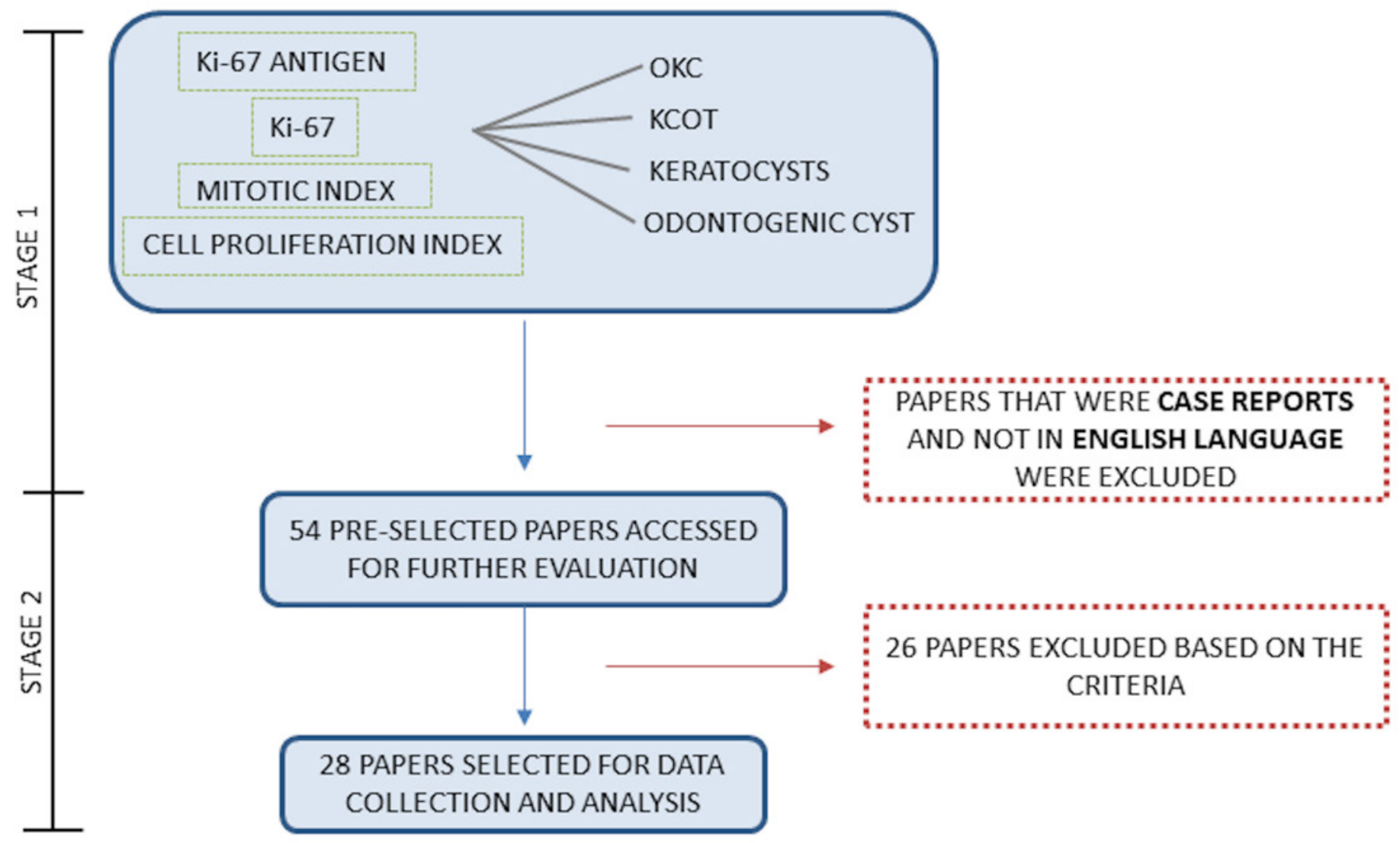

Figure 1. Flowchart of the articles selected for this literature review, from the initial identification to the final selection for review 
After the analysis of all these papers on the second stage, 28 articles were selected according to the described criteria and all relevant data were obtained from these papers: Ki-67 PI, number of analyzed cases and the immunohistochemistry analysis method in each study (Figure 1). Table 1 describes the reasons for the exclusion of 26 articles.

\section{Results}

The selected papers were divided into two groups for comparison: articles that show the index as mean (Table 2) and articles that present it as median (Table 3), because it is not possible to compare these different values.

Table 1. Number and reasons of excluded articles

\begin{tabular}{l|c}
\hline \multicolumn{1}{c}{ REASONS FOR THE EXCLUSION } & N OF ARTICLES $^{\circ}$ \\
\hline No cell proliferation index & 6 \\
\hline Index expressed only as a graphic, making it impossible to precise the PI & 2 \\
\hline Unclear methodology & 11 \\
\hline Impossible to reach a single PI value with the information on the paper & 2 \\
\hline PI calculated counting the positive cells per millimeters of basal membrane & 1 \\
\hline $\begin{array}{l}\text { Article with median and divided into two scores: more than 10\% and less than 10\% of } \\
\text { immunopositivity. }\end{array}$ & 1 \\
\hline The authors did not provide the PI separately for syndromic OKC and sporadic OKC &
\end{tabular}

Table 2. Articles with $\mathrm{Pl}$ as mean

\begin{tabular}{|c|c|c|c|c|c|c|c|c|}
\hline ARTICLE & YEAR & $\mathbf{n}$ & MEAN (\%) & SD (\%) & $\mathbf{M}$ & FIELDS & CELLS & $\mathbf{L}$ \\
\hline Ninomiya et al.31 & 2002 & 25 & $26.20 \%$ & $4.10 \%$ & x100 & 3 & 1000 & - \\
\hline Kim et al.21 & 2003 & 32 & $18.41 \%$ & $12.00 \%$ & $x 200$ & 5 RAF & - & - \\
\hline Kaplan et al.25 & 2004 & 45 & $10.00 \%$ & - & $x 400$ & $10 \mathrm{CF}$ & - & - \\
\hline Kichi et al.20 & 2005 & 20 & $18.50 \%$ & $1.50 \%$ & - & $10 \mathrm{RAF}$ & 500 & $\mathrm{~B} / \mathrm{SB} / \mathrm{S}$ \\
\hline Clark et al.24 & 2006 & 16 & $19.90 \%$ & - & - & - & 500 & - \\
\hline Gonzalez-Moles et al.30 & 2006 & 29 & $22.50 \%$ & $11.30 \%$ & $x 400$ & $4 \mathrm{RAF}$ & - & $B / S B$ \\
\hline Gadbail et al.13 & 2009 & 36 & $12.20 \%$ & $4.69 \%$ & $x 400$ & 10 RAF & 1000 & $\mathrm{~B} / \mathrm{SB} / \mathrm{S}$ \\
\hline De-Vicente et al.18 & 2010 & 11 & $40.00 \%$ & - & - & $\mathrm{CF}$ & 200 & - \\
\hline De-Oliveira et al.17 & 2011 & 13 & $19.98 \%$ & $11.66 \%$ & $x 400$ & 5 REF & - & $B / S B$ \\
\hline Gadbail et al.8 & 2011 & 38 & $14.64 \%$ & $3.52 \%$ & $x 400$ & $10 \mathrm{RAF}$ & 1000 & $\mathrm{~B} / \mathrm{SB} / \mathrm{S}$ \\
\hline Gadbail et al.11 & 2012 & 32 & $12.92 \%$ & $4.23 \%$ & $x 400$ & $10 \mathrm{RAF}$ & 1000 & - \\
\hline Guler et al.16 & 2012 & 7 & $16.00 \%$ & $13.46 \%$ & - & - & 100 & - \\
\hline Kadlub et al.28 & 2013 & 5 & $51.43 \%$ & - & $x 400$ & $10 \mathrm{RAF}$ & - & - \\
\hline Alur et al.22 & 2014 & 3 & $30.00 \%$ & - & $x 400$ & $10 \mathrm{RAF}$ & 1000 & $B / S B$ \\
\hline Ramos et al.15 & 2014 & 11 & $25.30 \%$ & $11.10 \%$ & $x 400$ & $10 \mathrm{CF}$ & 1000 & - \\
\hline Johann et al.10 & 2015 & 8 & $13.00 \%$ & - & $x 400$ & - & - & $\mathrm{B} / \mathrm{SB} / \mathrm{S}$ \\
\hline Cosarca et al.14 & 2016 & 20 & $22.40 \%$ & - & $x 400$ & - & 100 & $B / S B$ \\
\hline Awni et al.23 & 2017 & 14 & $10.83 \%$ & $5.00 \%$ & $x 400$ & 5 RAF & - & $\mathrm{B} / \mathrm{SB}$ \\
\hline Ledderhof et al.27 & 2017 & 14 & $18.64 \%$ & - & $x 200$ & $5 \mathrm{RAF}$ & 500 & - \\
\hline Zivkovic et al.26 & 2017 & 30 & $19.00 \%$ & - & - & 5 REF & - & - \\
\hline Modi et al.5 & 2018 & 15 & $12.76 \%$ & $4.78 \%$ & $x 400$ & 5 RAF & 1000 & $\mathrm{~B} / \mathrm{SB} / \mathrm{S}$ \\
\hline Doll et al.4 & 2018 & $54 *$ & $21.80 \%$ & $13.20 \%$ & $x 400$ & 10 & 1000 & - \\
\hline
\end{tabular}

$\mathrm{M}=$ magnification; $\mathrm{RAF}=$ randomly selected fields; $\mathrm{REF}=$ representative fields; $\mathrm{CF}=$ consecutive fields; $\mathrm{L}=$ evaluated layers; $\mathrm{B}=$ basal layer; $\mathrm{SB}=$ suprabasal layer; $S=$ superficial layer; "-"= no data available.

*Authors did not say how many samples of sporadic OKC were evaluated, they consider that 54 lesions included sporadic and syndromic OKC. But the indexes were given separately. 
Table 3. Articles with PI as median

\begin{tabular}{|c|c|c|c|c|c|c|c|c|}
\hline ARTICLE & YEAR & $\mathbf{N}$ & MEDIAN (\%) & VARIATION (\%) & M & FIELDS & CELLS & $\mathbf{L}$ \\
\hline Mateus et al.19 & 2008 & 11 & $9.83 \%$ & $7.19-19.78 \%$ & $x 400$ & 10 & - & $\mathrm{B} / \mathrm{SB} / \mathrm{S}$ \\
\hline Johann et al.12 & 2011 & 8 & $12.00 \%$ & - & $x 400$ & - & - & $B / S B$ \\
\hline Amaral et al. 6 & 2012 & 11 & $9.83 \%$ & $7.19-19.78 \%$ & $x 400$ & 10 & - & $\mathrm{B} / \mathrm{SB} / \mathrm{S}$ \\
\hline Selvi et al.29 & 2012 & 22 & $3.50 \%$ & $3-4 \%$ & $x 400$ & $5 \mathrm{CF}$ & - & - \\
\hline Metqud et al.7 & 2013 & 15 & $10.91 \%$ & $8.29-20.49 \%$ & $x 400$ & 10 & - & $\mathrm{B} / \mathrm{SB} / \mathrm{S}$ \\
\hline Naruse et al.9 & 2017 & 52 & $5.00 \%$ & $0-17.3 \%$ & - & $5 \mathrm{RAF}$ & - & $B / S B$ \\
\hline
\end{tabular}

$\mathrm{M}=$ Magnification; RAF = randomly selected fields; $\mathrm{CF}=$ consecutive fields; $\mathrm{L}=$ evaluated layers; $\mathrm{B}=$ basal layer; $\mathrm{SB}=$ suprabasal layer; $\mathrm{S}=$ superficial layer; "- "= no data available.

Three papers divided the indexes into layers (basal and parabasal). ${ }^{14,17,23}$ One provided only the number of positive cells and the total number of cells counted but did not provide a PI. ${ }^{24}$ Two papers divided the OKC evaluation according to inflammatory density ${ }^{25}$ and in follicular and extrafollicular OKC. ${ }^{21}$ To include these papers in our study, an overall PI was calculated for each study. All data collected are shown in Tables 2 and 3.

\section{Discussion}

The classification of OKC has changed over the years and many studies are being developed to determine a reliable classification, if it is a cyst or a tumor, seeking to define the best treatment and prognosis for this lesion. Some studies try to determine the nature of OKC through the cell proliferation index using Ki-67. But almost all papers present different methodologies, as well as different results. Therefore, this study analyzed and compared these articles and their methodologies to know how the PI was calculated.

Large variations of PI values can be observed in the selected articles, from $10 \%$ to $51.43 \%$ as mean, and from $3.5 \%$ to $12 \%$ as median. This can be explained by the different methods used in each of the analyzed papers.

The magnification is a methodological variable. Most authors used $\mathrm{x} 400$, others did the count at $\mathrm{x} 200$ or $\mathrm{x} 100$, which can impact the total number of visualized cells. This difference can be observed in Tables 1 and 2, where the authors indicate the number of cells that were evaluated by field.

The number of analyzed fields and how they were chosen are also factors that may have impact on the calculation of the percentage of positive cells: some authors select random, continuous or representative fields. Any parameter that changes the total number of evaluated cells might influence the PI, i.e., the higher the number of analyzed fields, the higher the number of cells. In addition, all tissues have fields that are considered a "hotspot", where greater immunostaining occurs; thus, depending on the selection of fields, this may also influence the result. When papers mentioned representative fields, the criteria used for such selection was not explained, so we considered this feature as "hotspot".
The location of immunopositive cells is also an important feature. Some authors analyzed all epithelial layers: basal, suprabasal and superficial, while others analyzed only the basal and suprabasal layer. This variable may also have impact on the total number of evaluated cells.

Considering the papers that calculated the PI as mean, the indexes varied from $10 \%$ to $51.43 \%$ and the mean of these results is $20.70 \%$. This shows a discrepancy among the results, mainly in the PI obtained by Kadlub et al. ${ }^{28}$ (51.43\%). However, we can verify that most values are very close, ranging from $10 \%$ to $25 \%$ (in 18 of 22 papers); therefore, the influence of the variables mentioned above may not be statically significant.

Focusing our analysis on Ledderhof et al. ${ }^{27}$ and Kim et al. ${ }^{21}$ we find that they used the same magnification (x200) and the same number of analyzed fields, and that cell number and the PI of both was similar: $18.64 \%$ and $18.41 \%$, respectively.

Despite such variance on OKC PI, it is interesting to note that according to the WHO's classification of odontogenic cysts and tumors (2017), ${ }^{3}$ when using Ki-67, the PI of some benign odontogenic tumors is low, like primordial odontogenic tumor (less than 2\%) and dentinogenic ghost cell tumor (less than 5\%). ${ }^{3}$ Therefore, further exploration of OKC's cell proliferation index are needed to actually verify the nature of this lesion.

Another example of how these variables may influence immunohistochemical results can be observed on Table 3: Amaral et al. ${ }^{6}$ and Mateus et al. ${ }^{19}$ used the same number of analyzed samples, magnification, fields and the same epithelial layers, so they found the same PI for OKC.

A high variation in the number of sample was also observed, from 3 to 52 among all papers. However, some articles showed similar PI using different number of sample, but with similar quantities of evaluated cells, showing that the number of sample may not have significant impact on the results.

For example, Kim et al. ${ }^{21}$ and Ledderhof et al. ${ }^{27}$ used the same magnification and number of analyzed fields, but a different number of sample, and achieved $18.41 \%$ and $18.64 \%$ 
PI, respectively. Amaral et al., ${ }^{6}$ Mateus et al. ${ }^{19}$ and Metqud $\&$ Grupta $^{7}$ used the same magnification, number of analyzed fields and epithelial layers, but as in the last example, with different sample numbers. Their PI were 9.83\%, $9.83 \%$ and $10.91 \%$, respectively. ${ }^{6,719}$ Both of these examples showed similar PI, which implies that the number of samples does not interfere on this calculation.

The main limitations of this systematic review are that the collected data are not the same across all studies, as well as the impossibility of performing a quantitative analysis of these results. Therefore, comparing the different studies using Ki-67 to evaluate the biological behavior of $\mathrm{OKC}$ is very difficult. Further and thorough research on these methodological variables are needed to confirm if they significantly influence PI results, from the statistical point of view, but many authors do not provide all relevant information of their methodology. For future researches, we suggest a standard evaluation of the proliferative activity and calculation of the index of these lesions, using the same magnification, number of cells and evaluating the entire epithelium.

\section{Conclusion}

From the results of this review, it is clear that most studies involving the immunohistochemical analysis with Ki67 antigen for evaluating the proliferative activity in OKC have unclear and non-standardized methodologies; therefore, the standardization of immunohistochemical analyses is necessary to improve and optimize future research, associating this antibody with the nature of these lesions.

\section{References}

1. Pindborg JJ, Kramer Jr. Histological Typing of Odontogenic Tumours. Jaw Cysts and Allied Lesions, 1th ed. Geneva: World Health Organization; 1971.

2. Barnes 1, Eveson JW, Reichart P, Sidransky D. Pathology and Genetics of Head and Neck Tumors, 1th ed. Lyon: IARCPress; 2005.

3. El-Naggar AK, Chan JKC, Grandis Jr, Takata T, Slootweg PJ. WHO Classification of head and neck tumors, 4th edition. Lyon: IARCPress; 2017.

4. Doll C, Dauter K, Jöhrens, Hartwig S, Voss JO, Klein M, et al. Clinical characteristics and immunohistochemical analysis of p53, Ki-67 and cyclin D1 in 80 odontogenic keratocysts. J Stomatol Oral Maxillofac Surg. 2018;161:1-6.

5. Modi TG, Chalishazar M, Kumar M. Expression of Ki-67 in odontogenic cysts: A comparative study between odontogenic keratocysts, radicular cysts and dentigerous cysts. J Oral Maxillofac Pathol. 2018;22(1):142-6.

6. Amaral FR, Mateus GCP, Bonisson LA, Andrade BAB, Mesquita RA, Horta MCR, et al. Cell Proliferation and Apoptosis in Ameloblastomas and Keratocystic Odontogenic Tumors. Braz Dent J. 2012;23(2):91-6.

7. Metqud R, Gupta K. Expression of cell cycle and apoptosis-related proteins in ameloblastoma and keratocystic odontogenic tumor. Annals of Diagnostic Pathology. 2013;518-21.

8. Gadbail AR, Hande A, Chaudhary M, Nikam A, Gawande M, Patil S, et al. Tumor angiogenesis in keratocystic odontogenic tumor assessed by using CD-105 antigen. J Oral Pathol Med. 2011;40:263-9

9. Naruse T, Yamashita K, Yanamoto S, Rokutanda S, Matsushita Y, Sakamoto $\mathrm{Y}$, et al. Histopathological and immunohistochemical study in keratocystic odontogenic tumors: Predictive factors of recurrence. Oncology Letters. 2017;13:3487-93.

10. Johann ACBR, Caldeira PC, Caliari MV, Gomez RS, Aguiar MCF, Mesquita RA. Metallothionein immunoexpression in non-syndromic and sundromic keratocystic odontogenic tumour. Med Oral Patol Cir Bucal. 2015;20(4):40812.

11. Gadbail AR, Patil R, Chaudhary M. OKC-expression of ki-67 and p53 protein in ameloblastoma and keratocystic odontogenic tumor. Act Odontologica Scandinavica. 2012;70:529-35.

12. Johann ACBR, Caldeira PC, Caliari MV, Abreu MHNG, Aguiar MCF, Mesquita RA. Metallothionein in the radicular, dentigerous, orthokeratinized odontogenic cysts and in keratocystic odontogenic tumor. J Oral Pathol Med. 2011;40:270-6.

13. Gadbail AR, Chaudhary M, Gawande M. Actual Proliferating Index and p53 protein expression as prognostic marker in odontogenic cysts. Oral Diseases. 2009;15:490-8.

14. Cosarca AS, Mocan SL, Pacurar M, Fulop E, Ormenisan A. The evaluation of Ki-67, p53, MCM3 and PCNA immunoexpressions at level of the dental follicle of impacted teeth, dentigerous cysts and keratocystic odontogenic tumors. Rom J Morphol Embryol. 2016;57(2):407-12.

15. Ramos GO, Costa A, Meurer M, Vieira DSC, Rivero ERC. Immunohistochemical analysis of matrix metalloproteinases (1, 2 and 9), ki-67, and myofibroblasts in keratocystic odontogenic tumors and pericoronal follicles. J Oral Pathol Med. 2014;43:282-8.
16. Güler N, Çomunoglu N, Cabbar F. Ki-67 and MCM-2 in Dental Follicle and Odontogenic Cysts: The Effects of Inflammation on Proliferative Markers. The Scientific World Journal. 2012;1-8.

17. De-Oliveira MG, Lauxen IS, Chaves ACM, Rados PV, Filho MS. Odontogenic epithelium: immunolabeling of Ki-67, EGFR and Survivin in Pericoronal Follicles, Dentigerous Cysts and Keratocystic Odontogenic Tumors. Head and Neck Pathol. 2011;5:1-7.

18. De-Vicente J, Torre-Iturraspe A, Gutiérrez A, Lequerica-Fernández P. Immunohistochemical Comparative study of the odontogenic keratocysts and other odontogenic lesions. Med Oral Patol Oral Cir Bucal. 2010;15(5):709-15. 19. Mateus GCP, Lanza GHSP, Moura PHR, Marigo HA, Horta MCR. Cell proliferation and apoptosis in keratocystis odontogenic tumors. Med Oral Patol Oral Cir Bucal. 2008;13(11):697-702.

20. Kichi E, Enokiya Y, Muramatsu T, Hashimoto S, Inoue T, Abiko Y, et al. Cell proliferation, apoptosis and apoptosis-related factors in odontogenic keratocysts ans in dentigerous cysts. J Oral Pathol Med. 2005;34:280-6.

21. Kim DK, Ahn SG, Kim J, Yoon JH. Comparative Ki-67 expression and apoptosis in the odontogenic keratocyst associated with or without an impacted tooth in addition to unilocular and multilocular varieties. Yonsei Med J. 2003;44(5):841-6.

22. Alur J, Narayan TV, Mohanty L, Shenoy S, Jamadar S, Shetty S. Ki-67 and p53 expression in solitary sporadic, syndrome associated and recurrent keratocystic odontogenic tumor. J Oral Maxillofac Pathol. 2014;18(1):21-5.

23. Awni S, Conn B. Decompression of keratocystis odontogenic tumors leading to increased fibrosis, but without any change in epitelial proliferation. Oral Surg Oral Med Oral Pathol Oral Radiol. 2017;123(6):634-44.

24. Clark P, Marker P, Bastian HL, Krogdahl A. Expression of p53, Ki-67, and EGFR in odontogenic keratocysts before and after decompression. J Oral Pathol Med. 2006;35:568-72.

25. Kaplan I, Hirshberg A. The correlation between epithelial cell proliferation and inflammation in odontogenic keratocyst. Oral Oncology. 2004;40:985-91.

26. Zivkovic ND, Mihailovic DS, Kostic MS, Cvetanovic AS, Mijovic ZZ, Milentijevic MVJ, et al. Markers of proliferation and cytokeratins in the differential diagnosis of jaw cysts. ENT-Ear, Nose \& Throat Journal. 2017;96(9):37683.

27. Ledderhof NJ, Caminiti MF, Bradley G, David K. Lam. Topical 5-Fluorouracil is a Novel Targeted Therapy for the Keratocystic Odontogenic Tumor. J Oral Maxillofac Surg. 2017;75:514-25.

28. Kadlub N, Coudert A, Gatibelza, Houmami NE, Soufir N, Ruhin-Poncet $\mathrm{B}$, et al. PTCH1 mutation and local aggressiveness of odontogenic keratocystic tumors in children: is there a relationship? Human Pathol. 2013;44:107178.

29. Selvi F, Tekkesin MS, Cakarer S, Isler SC, Keskin C. Keratocystic odontogenic tumors: predictive factors of recurrence by Ki-67 and AgNOR Labelling. Int J Med Sci. 2012;9(4):262-8.

30. González-Moles MA, Mosqueda-Taylor A, Delgado-Rodríguez M, 
Martínes-Mata G, Gil-Montoya A, Días-Franco MA, et al. Analysis of p53 protein by PAb240, Ki-67 expression and Human Papillomavirus DNA detection in different types of odontogenic keratocyst. Anticancer research. 2006;26:175-82.

31. Ninomiya T, Kubota Y, Koji T, Shirasuna K. Marsupialization inhibits interleukin-1a expression and epithelial cell proliferation in odontogenic keratocysts. J Oral Pathol Med. 2002;31:526-33.
32. Dandena VK, Thimmaiah SY, Kiresur MA, Hunsigi P, Roy S, Rashmi M. A comparative study of odontogenic keratocyst and orthokeratinized odontogenic cyst using Ki-67 and a smooth muscle actin. J Oral Maxillofac Pathol. 2017;21(3):458-9.

33. Dissanayake U, Johnson NW, Warnakulasuriya KAAS. Comparison of cell proliferation in the centre and advancing fronts of oral squamous cell carcinomas using Ki-67 index. Cell Prolif. 2003;36:225-64.

\section{Mini Curriculum and Author's Contribution}

1. Juliana Portes - DDS; MSc. Contribution: effective scientific and intellectual participation for the study; data acquisition, data interpretation; preparation and draft of the manuscript; critical review and final approval. ORCID: 0000-0003-0038-8909

2. Danielle Castex Conde Portes - DDS; PhD. Contribution: effective scientific and intellectual participation for the study; data acquisition, data interpretation; preparation and draft of the manuscript; critical review and final approval. ORCID: 0000-0002-8492-9145

3. Eliane Pedra Dias - MD; PhD. Contribution: effective scientific and intellectual participation for the study; critical review and final approval. ORCID: 0000-00020917-6091

Submitted: 01/13/2019 / Accepted for publication: 03/15/2019

Corresponding Author

Danielle Castex Conde

E-mail: daniellecastex@yahoo.com.br 